IJBPAS, January, 2021, 10(1): 08-20

ISSN: $2277-4998$

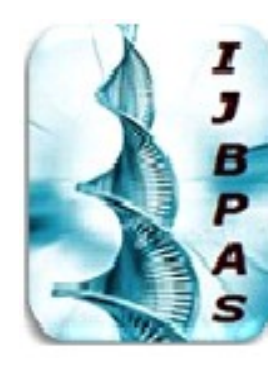

International Journal of Biology, Pharmaey and Allied Seiences (IJBPAS)

'A Bridge Betusen Caboratory and QRando'

WwW.ijbpas.com

DYSLEXIA - SPECIFIC LEARNING DISABILITY

SIVAPRAKASAM V

Professor in Pediatrics, Sri Lakshmi Narayana Institute of Medical Sciences, Puducherry and

Affiliated to BIHER

*Corresponding Author: Dr. V. Sivaprakasam: E Mail: vsiva pr@yahoo.co.in

Received $16^{\text {th }}$ Oct. 2020; Revised $14^{\text {th }}$ Nov. 2020; Accepted $9^{\text {th }}$ Dec. 2020; Available online $1^{\text {st }}$ Jan. 2021

https://doi.org/10.31032/IJBPAS/2021/10.1.1002

\begin{abstract}
Specific learning disability (SLD), dyslexia is a neuro-developmental and biological disorder. Incidence is 5-15\%. An Intelligent child with normal or above normal IQ, child who fails in a class, reads slowly - word by word, skips words, sentences ,hates reading is considered to have dyslexia. Writing slowly, poor handwriting ,reversal tendency, lot of spelling and grammar Mistakes labeled as dysgraphia. Poor in math is dyscalculia. Remedial teaching remains the mainstay of management. Government is also giving lot of concessions in the examinations. SLD is included in the disability act and poor children with dyslexia may get free remedial teaching. We need to identify all children irrespective of financial status with SLD.

Keywords: Learning disability, Dyslexia, Dysgraphia, Dyscalculia, Remedial teaching INTRODUCTION

\section{Points to Remember}

- Dyslexic children, have difficulty in reading, reads slowly word by word, hates reading, poor hand writing, will do lot of grammar mistake, lot of spelling mistake, reversal tendency in

reading and writing and difficulty with math

- These children need to be identified, at the age of 7 years.

- Their IQ is normal or above normal and have multiple intelligence.
\end{abstract}


- Remedial teaching is the main mode of management of these children.

- No drug is needed, unless associated co morbid condition like ADHD

- Government is giving lot of concessions to these children.

\section{Dyslexia - Specific Learning Disability}

Learning problem in children is increasingly recognized in India. Early identification of learning disability is absolutely vital, as early remediation and intervention has the best chance of favorable outcome. Learning disability affects $5-15 \%$ of school children $[\mathbf{1}, \mathbf{2}, \mathbf{3}]$. The symptoms of Dyslexia were first identified by Berkhan in 1881 and the term dyslexia is coined by Rudolf Berlin in 1881.

Dyslexia is a disorder in a child, who despite conventional class room experience, fails to attain the language skills, of reading, writing and spelling, commensurate with their intellectual abilities.

Specific learning disability (SpLD) is a group of neuro-developmental disorder manifesting as persistent difficulty in learning to efficiently read (dyslexia), write (dysgraphia) and perform mathematical calculations (dyscalculia) despite normal intelligence, conventional schooling, intact hearing and vision, adequate motivation and socio-cultural opportunity $[2,4]$.

\section{IAP Guideline Definition: [5]}

Learning disabilities (LD) are a heterogeneous group of disorders where the individual unexpectedly fails to competently acquire, retrieve and use information. The academic achievement is lower than expected, based on the child's overall intelligence. LD has been defined as a neurodevelopment disorder of biological origin manifesting in learning difficulties and problems in acquiring academic skills, which are markedly below age level.

Learning disability manifests during early school years and it is not attributed to intellectual disabilities, or neurological or motor disorders. The difficulties should last for at least six months, to warrant a diagnosis Eighty percent of SLD is reading disability dyslexia, $(4,6) 25 \%$ of the children will have ADHD as co-morbid condition (2, 6) which needs medication before remedial Teaching. The IQ will be $90-140 \%$ Dyslexia affects boys and girls equally. It is a lifelong condition. Definitive diagnosis is made at 7-8 years. No detention policy, (NDP) leads to delayed identification of learning problems [5].

Language is a system for human communication It has 5 components. Speech is the verbal expression of language. Core 
defect in dyslexic children is the lack of phonological awareness $[1,4,6]$.

Phonology: Phoneme is the smallest linguist unit of speech that signals a different sound [distinct speech sound].

e.g. $p, b$ are phoneme $[1,7]$.

Morphology: Morpheme is the smallest linguist unit with meaning. It may be prefix, suffix, or root word - $\operatorname{dogs} \operatorname{dog}+\mathrm{s} 2$ morphemes

Syntax is the rule system that governs the structure of a sentence" e.g. Ball hit the man" 'man the ball hit'

Semantics is the ability to obtain meaning from the words, sentences and other word combinations

Pragmatics is the use of language in social contexts

Dyslexic Children may have problem with any one or all 5 components

\section{Genetics of Dyslexia}

Both familial and heritable. There are $40 \%$ genetic predisposition for dyslexia. 23 to $65 \%$ children have a parent with dyslexia and $40 \%$ among siblings. Linkage study indicate loci in chromosome 2, 3, 6, 15 and 18. Affects both boys and girls equally [7]. Any insult to the developing brain, Pre-natal, natal, post natal and during infancy period may lead to SLD

\section{Types of SLD}

- Reading - Dyslexia

- Writing - Dysgraphia

- Oral (spoken) - Dysphasia

- Mathematics - Dyscalculia

- Motor in coordination - Dyspraxia

\section{Dyslexia - Difficulty in Reading}

It is caused by deficit in Phonological processing [8]. Reads very slowly, word by word, loses place, missing out lines or reading the same line again. Therefore needs to always keep finger below line being read. They hesitates to read aloud, hates reading and refuses to read. These children may try to sound out the individual elements of word, but is often unable to synthesize it into the correct word. E.g. b/e/g and then say bad [9].

\section{Other Features are}

Ignores punctuation, thus often confusing the meaning of the text.

Confusion with alphabet, shapes and positions $b$ as $d$ [9]

Confusion in words - was - saw (mirror image reading) Omission bet for belt, wet for went Addition played for play Substitution house for home Mispronounces some words such as:- help for held Puts syllables in the wrong order:- animal as aminal

They answers well in oral, but fails in written tests. Unable to tell a story. Difficulty in explaining with examples. Sounds are 
confused empty- entry. These children have poor memory- cannot recall sequence of letters [inefficient visual memory system]- no automatic reading. Concepts are reversedFloor for ceiling

\section{Reading Comprehension}

There is difficulty in understanding the meaning of what is read (e.g. may read text accurately but not understand the sequence, relationships, inferences, or deeper meanings of what is read). and poor in Reading comprehension. Difficulty in reading and understanding questions. If we read out question, the child can answer. Understands and learns better if someone reads out the same text to the child

\section{Dysgraphia-Writing Disability}

It is caused by a range of neurodevelopment weakness including problem with hand writing (fine motor \& grapho motor) and visual -spatial perception

Problem exclusively in spelling (also called encoding which is ability to use letter sound relationships effectively) in the absence of problem in written expression is more indicative of phonological processing deficit ie Dyslexia [5, 7].

Dysgraphia is often multi-factorial, due to impaired letter writing automaticity, finger motor sequencing challenges, organizational and elaborative difficulties and impaired visual word form which makes difficult to retrieve the visual of words requiring spelling.

Poor handwriting. Abnormal grip makes writing slow and laborious, notes are incomplete and do not make sense. These children are poor in remembering certain alphabets and unable to copy from board. Shows mirror writing. They do lot of spelling mistakes and grammar mistakes and writes letters in the wrong order e.g. Simon as Siomn, what as wtah

Inconsistent errors/sometimes correct spelling - e.g. apple, appel, aple [9]

Reverses letters and words - e.g. b as d, p as q, was as saw

Inverts letters - e.g. n-u, m-w, d-q, p-b, f-t

Omits letters - e.g. limp as lip, string as sing Adds letters - e.g. went as whent, what as whant

Spells the way the word sounds - BUSY as BIZZY

\section{Dyscalculia - Difficulty with Mathematics}

It is a neurological condition characterized by a problem with basic sense of number and quantity and difficult in retrieving note and math fact. (arithmetic combinations or calculations) difficulty with language of maths (correctly reading and understanding the text of word problems) and 
visual- spatial and organizational demands of math [5].

Change the shape 6 as 9 , position of numbers, 17 as 71 , Poor in number sense. These children lack mastery of basic addition, subtraction, multiplication and division combinations, difficulty in Algebra. They are poor in geometry; subtract bigger number from smaller one, difficulty in carrying over or borrowing sums. They may count from left to right, uses fingers for calculations even after 8 years of age.

\section{Dyspraxia}

Poor posture, awkward clumsy movements, poor handwriting ,immature behavior, lack of awareness of potential danger, difficulty writing at speed, lack of fluency in reading, Poor short term memory, difficulty in battening the shirt, tying the shoe lace [8].

\section{Psychological Effects which is Preventable}

School refusal, School failure, Drop out, Depression, Anxiety, Suicidal attempts, Intolerance and Anger, run away, lack of self confidence, emotional instability, loss of self-esteem, inferiority complex and poor socialization $[2,6,10]$.

\section{Co- Morbid Conditions with Dyslexia}

Attention deficit hyperactivity disorder (ADHD), conduct disorders oppositional defiant disorder, anxiety disorders, depression, tic disorders and Tourette's syndrome.

Though the confirmation of diagnosis of dyslexia can be done at 7 years, we can pick up children by early warning signs as early as 3 years and we can follow up these children till 7 years to confirm the diagnosis of dyslexia.

Early Pointers for Learning Disability [1, 9]

1. Speech delay

2. Missing of the crawling stage

3. Difficulty in buttoning the shirt

4. Difficulty in tying the shoe lace

5. Difficulty with rhymes

6. Difficulty with puzzle

Though we are not confirming diagnosis of dyslexia, early stimulation can be started at 3 years by phonics method of teaching, so that, we can reduce the severity of dyslexia [9].

\section{Diagnosis}

An intelligent child, who fails in a class, normal or above normal IQ (100-140), not performing well in school, dislike reading, read slowly, skips words, sentences, reversal tendency- was-saw. They write slowly, poor hand-writing, lot of spelling and grammar mistakes. Poor in mathematics, and algebra, there is a possibility of dyslexia [5]. 


\section{R/O Other Causes of Learning Disability} [9]

- Visual ailments

- Hearing problems

- Medical conditions

- Home atmosphere

- School aatmosphere

- ADHD

- Psychological problem

- Mental retardation

- Slow learners IQ- 70-89

Slow Learners- Below average cognetic abilities who are not disabled but struggle to cope up with traditional academic (3) demands of the regular class room. Only IQ assessment will be the differentiating feature, we need to do IQ testing with the help of clinical psychologist. If IQ $90-140$ with the features of learning problem we can give a provisional diagnosis as SLD. (9)

\section{Dsm.5-Diagnostic Criteria-SLD [12]}

A. Any one of the following symptoms that have persisted for at least 6 months,

- Inaccurate or slow and effortful word reading.

- Difficulty in understanding the meaning of what is read

- Difficulties with spelling (e.g. may add, omit or substitute letters)
- Difficulties with written expression (e.g. makes multiple grammatical or punctuation errors within sentences

- Difficulties in mastering number sense (Math)

- Difficulties with mathematical reasoning

B. Two grade low for the age

C. Onset before 7 years

D. Rule out other causes

\section{Assessment}

There are several Tools available for Screening, Diagnosis, and Assessment for LD. Pediatrician need to diagnose with the guidelines by IAP and by DSM -5 Criteria. These are the list of important Tools

SLD-SQ Specific Learning Disability Questionnaire, used in the studies conducted in India [14].

Nimhans Index to assess children with SLD [15] (National Institute of Mental Health and Neuro sciences) Level 1 -- 5-7 years Level 2 --- 8-12 years

IQ Assessment: [5]

BKT: Binet-Kamat Test

Woodcock Johnson Tests of

Cognitive Ability (3rd edition; age two and above) or

Malin's Intelligence Scale for Indian Children (for children 
6 years and above), which is the Indian adaptation of

Wechsler Intelligence Scale for Children (WISC);

Achievement: Woodcock Johnson III - tests of

Achievement for children; Nelson Denny Reading Test

for high school and college students;

Cognitive Processing Abilities: Woodcock Johnson

Psycho-Educational Battery Revised (Part 1)

[5]

\section{Practical Approach}

All children attending pediatric outpatient clinic, ask about their academic performance, whether they love to read or not and their marks. When an intelligent child with poor academic performance, persistence low marks in exams and with any one of the problems like difficulty in reading, reads slowly, poor hand writing, lot of spelling mistakes, poor hand writing and poor in math, we need to, suspect learning disability, We need to fix an appointment and ask them to come for evaluation at our convenient time in any afternoon with their notebooks, mark sheets and books. We need to do a simple clinical examination to $\mathrm{R} / \mathrm{O}$ medical problem, ADHD, intellectual disability (MR).
We need to have Graded paragraph for testing the reading efficiency and to give it for copying . List of Dictation words. Also Graded sums for addition, subtraction, Multiplication and Division. Usually the Reading level will be 2 grade less for his age Reading: Ask to read a simple passage. Note the speed, errors in reading like omit letters substitute letters, skipping words or sentences, guess work and mispronunciation

\section{Comprehension Skills [9]}

Give one paragraph of reading material and ask him to read out, ask simple questions, see the answers. If he is not answering read out the paragraph to him and see whether he is able to grasp the main idea, and answers all questions.

Writing: Look at the answer papers, and the class note books, for spelling mistakes, poor hand writing, reversal tendency, incomplete answers. Asking him to copy a paragraph and note the speed of writing, irregular hand writing.

Give simple dictation words and see the spelling,

Maths: Ask them to identify numbers 1, 2, 3, 4. Give simple addition and subtraction sums. 
Rule Out Other Causes

Send for IQ Assessment \& Academic Assessment

$\mathrm{IQ}=$ mental age/chronological age

Dyslexic Children will have IQ 90-140., IQ

done by by clinical psychologist.

Academic assessment by LD specialist - assesses the reading level, writing level and the mathematical level

\section{Assessment by Child Psychiatrist}

To rule out any psychological problem which occurs as co-morbid or as a effect of LD

\section{Final Assessment by Developmental Pediatrician}

To rule out any other problem and co morbid conditions, to confirm dyslexia, and to help in planning the IEP, and to guide them to get a certificate.

\section{Principles of Management [13]}

1. Remedial education - Special educator Educational assessment, IEP

2. Occupational therapy - e.g. Handwriting skills

3. Speech and language pathologist

4. Counseling and guidance to family psychologist/counselor
5. Treatment of associated problems General pediatricians, developmental pediatricians, psychiatrist

6. Career counseling - school along with parents

Remedial Teaching $(2,6,16,17,18)$

When a child is not able to understand in a way we are teaching, we will change the way of teaching so that the child will understand. It is costly and not affordable by all parents .Remedial teaching 2-3 hrs a day for 3 days a week for at least for 6 months is advocated. After academic assessment they formulate individual education plan. A teacher can handle only 2 3 children at a time Due to high plasticity of the central Nervous system in early years Remedial education began early when the child is in Primary School [5].

In normal children a centre will be activated when the child reads (Figure 1). In dyslexic children it is not activated (Figure 2). After remedial teaching for 6 months a new centre will be activated in the frontal lobe (Figure 3). In 10-15\% of the children even after remedial teaching no activation seen Figure 1 [19]. 


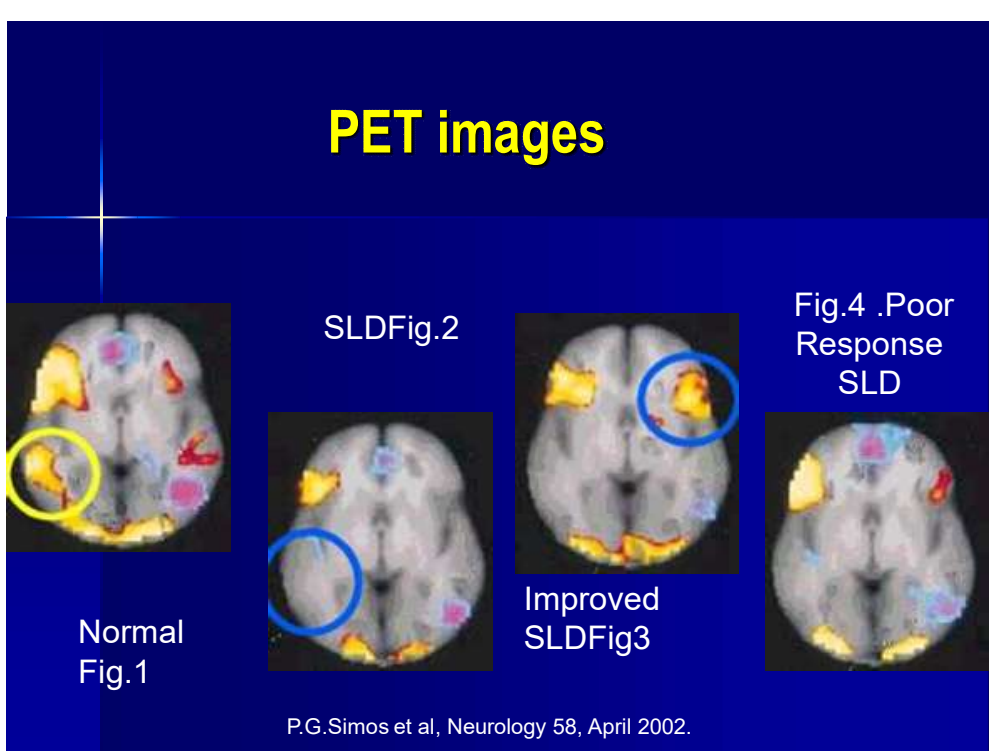

Figure 1: Changes observed in the Brain in Dyslexic Children in PET Scan (Figure 1, \&2)

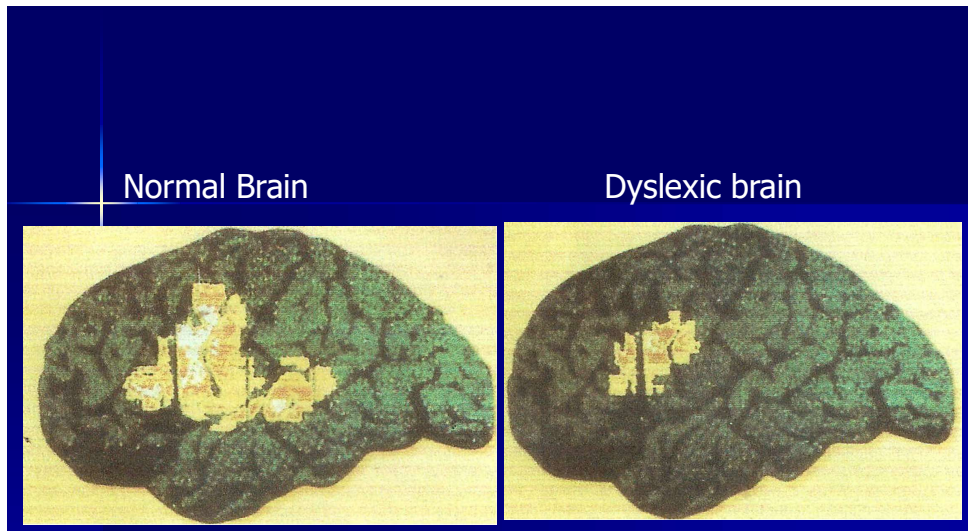

from: Frith C, Frith U.

A biological marker for dyslexia. Nature.

\section{6;382:19.)}

Figure 2: Area of activation in the brain in a Normal child and a Dyslexic child when the child reads [20]

\section{Government Programs to Help Dyslexic} Children

SSA: In 2011 Government launched SSA Serva Shiksha Abhiyan (education for all) that aims to provide useful and relevant education to all children including children with disabilities $[\mathbf{1 3}, \mathbf{2 1}]$. Inclusive education: Dyslexic children will be getting new method of teaching in the regular classes itself. Training of attention concentration, correction of spelling and grammar mistakes will be done in the regular classes. Every school should have resource room [18].

Resource room: Children will attend regular school and in the evening remedial teaching will be given in the resource room. 
Remedial teacher, councilor, social worker, clinical psychologist, occupational therapist will constitute a Team [1, 20].

\section{RBSK-Rashtriya Bal Swasthya Karyakram [13, 22]}

Early detection and early intervention - Disease, disabilities, defficiencies, developmental problems. Funded by NRHM. Medical officer, cclinical Psychologist, specialeeducator, ooccupational therapist and ssocial worker will constitute a Team [13, 22].

District early intervention centre (DEIC) $[13,22]$

Every district will have a centre to prevent or minimize the effects of selected health conditions. Management of defects at birth, deficiencies, disease and developmental delay including disabilities among children zero to 18 years

\section{Counseling of Parents}

We need to spend some time to explain about dyslexia and clear their doubts and to bring down their anxiety. We need to help them to get remedial Teaching. We need to assure them and guarantee them that their children will reach very big heights and will be successful in life.

\section{Parents Should Know}

The Problem of dyslexia is neuro developmental and biological. It involves brain circuits, and EEG, MRI \& CT are not needed. Not a disease or illness, no drugs needed. Usually genetic and so child is not responsible. Early intervention - remedial teaching works well. Parents should know the weakness and strength like, Poor selfesteem, inferiority complex. Parents should not- compare, use rude words, or beating the child and not to discuss about him in front of others, but learn how to help them.

\section{Counseling of Children}

We need to tell them that they have a problem which is not due to their fault, and motivate them to overcome the problem. They need to spend more time and work hard. We need to council them not to worry and they will be alright. We should prize them and reward them for small achievements.

\section{Government Concessions}

Government is giving lot of concessions for Dyslexic Children to compete with normal children in the exams.

One hour extra time in public exams. No mark reduction for grammar and spelling mistakes. Can use calculator in math's exam. Exemption from writing one language. Can use a scriber. In a study, the mean total marks increased by $22 \%$ from $41 \%$ before to $63 \%$ after availing the provisions $[\mathbf{1 3}, \mathbf{2 3}]$. 
Why we need to Identify Dyslexic

\section{Children}

1. Burden of learning disability is very high $-10 \%$ of students

2. It is only tip of the iceberg

3. Identifying at the age 7 will be ideal for better results.

4. In spite of good IQ (100 to 140), they are failing in the class

5. Remedial teaching works well

6. Children suffer internally due to pressure from parents and schools

7. LD children are hurt by teachers, parents, friends in spite of the fact they are not at fault

8. Hidden tragedy

9. Unable to cope up with the educational pressure, parental pressure lead to many psychological problems

10. Comprehensive treatment with multidisciplinary approach can be done under one roof [5].

11. SLD is included in the Disability ACT2017, We get enough funds for free remedial teaching(24)

12. When we identify them early and give remedial measures and get the government concessions, they will be able to perform well in studies and pass 12th Standard and may become post graduates and professionals. If we fail to identify them early they get lot of problems like repeated failure, rejection, poor self esteem, anxiety, disturbed, insecure, delinquency, school drop outs and become social misfits [5].

\section{CONCLUSION}

As we don't have enough people to identify all these children in the community, we have to train the pediatricians and teachers to identify these children from the community and give them proper training.

Our Dream is to identify all Children with Learning Disability, Dyslexia in our Nation, with in the year 2020 and to provide free remedial teaching with the Help of Government as the Learning disability is included in the disability act!

We did a pilot project in 20 Schools, and Screened 2000 children.

Results of the Pilot Project

\begin{tabular}{|c|c|}
\hline Problem & No of Children \\
\hline Dyslexia SLD & 60 \\
\hline Slow Learners & 15 \\
\hline Mild MR & 20 \\
\hline Moderate MR & 2 \\
\hline Vision Problem & 1 \\
\hline Hearing Problem & 2 \\
\hline $\begin{array}{l}\text { Total No of LD } \\
\text { Children }\end{array}$ & 100 \\
\hline
\end{tabular}




\section{REFERENCES}

[1] Sunil Karande et al, Managing Specific Learning Disabilities schools in India, Indian pediatrics2011; 48: 515-520.

[2] Lagae L. Learning disabilities: definitions, epidemiology, diagnosis, and intervention strategies. Pediatr. Clin North Am. 2008; 55: 1259-68.

[3] Katusic SK, Colligan RC, Barbaresi WJ, Schaid DJ, Jacobsen SJ. Incidence of reading disability in a population based birth cohort, 19761982, Rochester, Minn. Mayo Clin Proc. 2001; 76: 1081-92.

[4] Shaywitz SE. Dyslexia. N Engl J Med., 1998; 338: 307-12.

[5] MKC Nair, Chhayaprasth, Anjanbhatachariya, SSKamath and Samir Dhalwal, Consensus statement of Indian Academy of Pediatrics on evaluation and Management of Learning disability, March 29 2017, Pii; SO974755911600057, Indian pediatrics July 2017-574-580

[6] Karande S, Kulkarni M. Specific learning disability: the invisible handicap. Indian Pediatr 2005; 42: 315-9.

[7] Nelson Text book of Pediatrics.
[8] University of Kerala Text book on Developmental neurology CDC PGDN.

[9] Poor Scholastic performance module (PSPP) IAP president Action Plan 2011

[10] Karande S, Kulkarni M. Poor school performance. Indian J Pediatr 2005; 72: 961-7.

[11]Children and learning Difficulties (Book) by Onida Nakara,, Allied publishers limited, New Delhi

[12] American Psychiatric Association. Diagnostic and Statistical manual of mental disorders (DSM-5®). $5^{\text {th }}$ ed.

[13] Cradle to Crayon module IAP President Action Plan 2016.

[14] Padhy SK, Goel S, Das SS, Sarkar S, Sharma V, Panigrahi M. Prevalence and patterns of learning disabilities in schoolchildren. Indian $\mathrm{J}$ Pediatr. 2016; 83: 300-6

[15] Kapur M, John A， Rozario J, Oommen A. NIMHANS Index of Specific Learning Disabilities. Psychological Assessment of Children in the Clinical Setting. Department of Clinical Psychology, National Institute of Mental Health 
and Neurosciences; Bangalore. 2002: 88-126.

[16] McDonnell L, McLaughlin M, Morison P. Educating one and all: students with disabilities and standards-based reform. Washington DC: National Academy Press; 1997;p 204

[17] Dakin KE. Educational assessment and remediation of learning disabilities. Semin Neurol., 1991; 11: 42-9.

[18] Alexander AW, Slinger-Constant AM. Current status of treatments for dyslexia: Critical review. J Child Neurol., 2004; 19: 744-58.

[19] Frith C, Frith U. A biological marker for dyslexia. Nature1996; 382 (6586): 19-20

[20] Lagae L. Learning disabilities: definitions, epidemiology, diagnosis, and intervention strategies. Pediatr Clin North Am. 2008; 55: 1259-68.

[21] Kainth GS. A mission approach to Sarva Shiksha Abhiyan. Econ Polit Wkly. 2006; 41: 3288-91.

[22] Operational Guidelines on Rashtriya Bal Swasthya Karyakram (RSBK). Ministry of Health and Family Welfare, Government of India. http://www.pbnrhm.org/docs/rbskgui delines.pdf. Accessed. January 13, 2017.

[23] Kamala R. Specific learning disabilities in India: Rights, issues and challenges. Indian J Appl Res. 2014; 4(5). Available from: https://www.worldwidejournals.com indian-journal-of-applied-research(IJAR)/file.php?val=May_2014_139896 7503_e9548_190.pdf. Accessed January 13, 2017.

[24] Unni JC. Specific learning disability and the amended "Persons with disability act". Indian Pediatrics. 2012; 49. 